\title{
The effect of repair technique on postoperative right-sided obstruction in patients with truncus arteriosus
}

\author{
Jonathan M. Chen, MD \\ Julie S. Glickstein, $M D^{\mathrm{b}}$ \\ Ryan R. Davies, MDa \\ Michelle L. Mercando, $\mathrm{BA}^{\mathrm{a}}$ \\ William E. Hellenbrand, $M D^{\mathrm{b}}$ \\ Ralph S. Mosca, MD \\ Jan M. Quaegebeur, MDa
}

From the Divisions of Cardiothoracic Surgery $^{\mathrm{a}}$ and Pediatric Cardiology, ${ }^{\mathrm{b}}$ Columbia University College of Physicians and Surgeons, New York, NY.

Read at the Eighty-fourth Annual Meeting of The American Association for Thoracic Surgery, Toronto, Ontario, Canada, April 25-28, 2004.

Received for publication April 21, 2004; revisions received Oct 6, 2004; accepted for publication Oct 11, 2004

Address for reprints: Jonathan M. Chen, MD, Pediatric Cardiac Surgery, Cornell Campus, New York Presbyterian Hospital, 525 East 68th St, Box 110, Suite F695B, New York, NY 10021 (E-mail: jmc23@ columbia.edu).

J Thorac Cardiovasc Surg 2005;129:559-68

$0022-5223 / \$ 30.00$

Copyright $\odot 2005$ by The American Association for Thoracic Surgery

doi:10.1016/j.jtcvs.2004.10.018
Objectives: We reviewed our experience with repair of truncus arteriosus to assess the effect of type of right ventricular outflow tract reconstruction on perioperative morbidity, survival, and freedom from catheter-based interventions and reoperation.

Methods: Patients undergoing repair of truncus arteriosus from June 1990 through February 2004 were evaluated on the basis of operative procedure regarding preoperative and postoperative variables, the need for postoperative catheter-based intervention or reoperation, and survival on the basis of univariate, multivariable, and actuarial analyses.

Results: Of 54 study patients, 15 (28\%) received a valved homograft, and 39 (72\%) received a direct connection with a variety of hood materials. Five (9.1\%) patients died. Valved homograft recipients were more likely to require reoperation than patients receiving direct connections ( $40 \%$ vs $15 \%, P=.046$ ); however, valved homograft and direct connection recipients had a similar incidence of the combined end point of reoperation or catheter-based intervention $(40.0 \%$ vs $37.5 \%, P=.865)$. Univariate and multivariable modeling demonstrated use of valved homografts or direct connections with an autologous pericardial hood to be predictive of the need for later catheter-based intervention or reoperation. Actuarial analysis demonstrated a trend toward improved outcomes in the direct connection group and within the direct connection cohort, a statistically significant difference on the basis of hood type.

Conclusions: Although the direct connection technique might not prevent later catheterbased intervention, it does reduce the need for reoperation. Outcomes among direct connection recipients were associated with hood type: polytetrafluoroethylene hoods (W. L. Gore \& Associates, Inc, Tempe, Ariz) had the lowest rate of reintervention, and untreated autologous pericardial hoods had the highest rate of reintervention. We report excellent outcomes with primary repair of truncus arteriosus. Where anatomically appropriate, we advocate the direct connection technique.

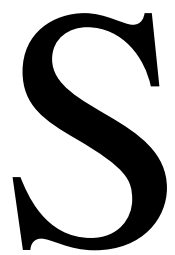

ince the first report of successful surgical correction of truncus arteriosus (TA) in 1965, several advances have favorably affected overall results. ${ }^{1}$ Although the tenets of the repair have not changed substantially over time, considerable debate persists as to the best method to establish right ventricle (RV)-pulmonary artery (PA) continuity. Traditional techniques have favored the use of valved homografts (VHs), accepting with it the obligatory need for later replacement. More recently, others have promoted the so-called direct connection (DC), which obviates the need for allograft tissue by directly anastomosing the RV to the PA confluence. ${ }^{2,3}$ 


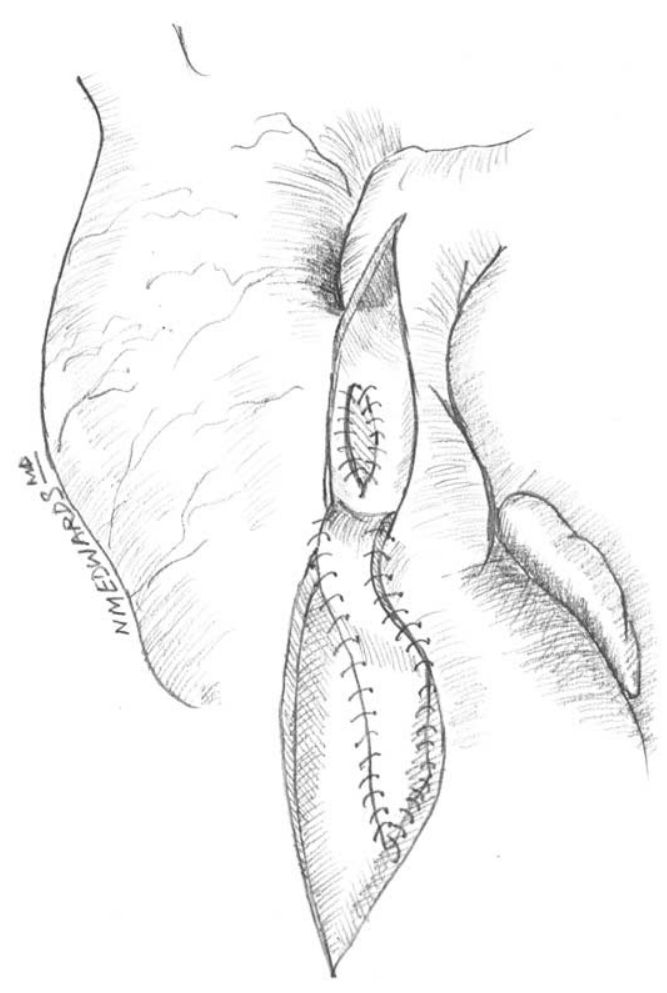

Figure 1. Schematic representation of the trapdoor incision used to bridge the distance between the pulmonary arteriotomy and the top of the right ventriculotomy. The door forms the back wall of the DC in this arrangement.

In theory, the DC technique preserves the potential for growth by using the patient's own tissue for the repair. Several materials have been applied to complete the hood of the connection in an attempt to limit the distortion of branch PAs and to allow for an unobstructed right ventricular outflow tract (RVOT). Although it has been suggested that the DC might reduce the need for later reoperation, whether this technique actually abolishes the need for reoperation or instead replaces it with other catheter-based interventions (CBIs; eg, stent placement and balloon angioplasty) remains unclear.

We evaluated our experience with primary repair of TA both with VH conduits and with DC using a variety of hood materials. In so doing, we sought to evaluate our evolving experience and to assess the effect of type of RVOT reconstruction on perioperative morbidity, survival, and freedom from $\mathrm{CBI}$ and reoperation.

\section{Methods \\ Patients}

We reviewed the records of all patients undergoing primary repair of TA from June 1990 through February 2004 at the Children's Hospital of New York. For the purposes of analysis, 4 other children who had undergone their first repair at other institutions and patients with hemitruncus were not included. Functional and demographic parameters evaluated included age, associated anatomic anomalies, DiGeorge syndrome, preoperative truncal valve morphology and function, operative procedure, need for postoperative CBI (balloon or stent) or reoperation and most recent echocardiogram. Survival and late functional data were based on follow-up with referring cardiologists and, where indicated, direct telephone interview.

\section{Operative Procedure}

Repair of TA was performed with hypothermic cardiopulmonary bypass and occasionally with deep hypothermic circulatory arrest when aortic arch repair was required. Cold blood cardioplegia was used for myocardial protection, with topical cold saline or ice slush.

VH technique (15 patients). The PAs were excised carefully from the ascending aorta. The defect in the ascending aorta was then closed with a polytetrafluoroethylene (PTFE) patch (GoreTex patch; W. L. Gore \& Associates, Inc, Tempe, Ariz). A vertical right ventriculotomy was then performed, and the ventricular septal defect was closed, again with a PTFE patch. RV-PA continuity was then established with a VH in 15 patients; in 7 patients this was a pulmonary homograft, and in 8 it was an aortic homograft. Aortic homograft sizes ranged from 9 to $11 \mathrm{~mm}$, whereas all but 2 pulmonary homografts (which were 9 and $11 \mathrm{~mm}$ ) were downsized from larger $(21-24 \mathrm{~mm})$ to smaller $(12-16 \mathrm{~mm})$ sizes; in these grafts valve competency was preserved. The conduit was anastomosed first to the PA and then was anastomosed posteriorly to the RV by using a hood over the anterior portion to prevent distortion; for aortic homografts, the hood was comprised of mitral valve tissue, and for pulmonary homografts, the hood was comprised of PA homograft tissue.

DC technique (40 patients). An incision was made in the truncus just left of midline so as not to compromise the aortic lumen. The truncal valve was inspected, and the defect was closed as above. The PAs, however, were left in situ; if the pulmonary arteriotomy was immediately adjacent to the upper portion of the right ventriculotomy, often the small portion of epicardium bridging this distance was used as the back wall of the DC. In other cases, a trapdoor-type incision was made in the PA and turned down toward the ventricle to bridge the distance between the PA and the RV (Figure 1). Several materials were used to reconstruct the anterior hood so as to prevent PA distortion or RVOT obstruction.

\section{Postoperative Interventions}

Indications for postoperative CBI are also in evolution. With the increasing recognition of the potential problems of RVOT or branch PA stenosis with either method of repair, our threshold to intervene has been substantially reduced. Our indications currently include the following: (1) persistently increased RV pressures (greater than two thirds systemic); (2) persistent right-to-left shunting and subsequent cyanosis in the setting of increased RV pressures; (3) substantial PA distortion (near occlusion) with risk of loss of branch PA flow; or (4) evidence of substantial disparity in pulmonary blood flow (by means of quantitative magnetic resonance imaging assessment or by means of radionucleotide perfusion scanning) associated with significant branch PA stenosis. 
TABLE 1. Reoperations for right-sided obstruction in the truncus cohort

\begin{tabular}{|c|c|c|c|c|}
\hline Patient & Age & First repair & Interval & Reoperation \\
\hline 1 & $13 d$ & Direct connection (autologous pericardium) & $9 \mathrm{~d}$ & $\begin{array}{l}\text { Revision of RVOT (obstruction) with autologous } \\
\text { pericardium }\end{array}$ \\
\hline 2 & $38 \mathrm{~d}$ & Direct Connection (autologous pericardium) & $2.9 \mathrm{mo}$ & $\begin{array}{l}\text { Revision of outflow patch (aneurysmal) with } \\
\text { bovine pericardium }\end{array}$ \\
\hline 3 & $30 \mathrm{~d}$ & 9-mm Aortic homograft & $3.8 \mathrm{mo}$ & $\begin{array}{l}\text { Conduit replacement (downsized pulmonary } \\
\text { homograft) for conduit obstruction }\end{array}$ \\
\hline 4 & $11 \mathrm{~d}$ & Direct connection (autologous pericardium) & $5 \mathrm{mo}$ & $\begin{array}{l}\text { Revision of outflow patch (aneurysmal) with } \\
\text { PTFE, repair PA bifurcation }\end{array}$ \\
\hline \multirow[t]{2}{*}{5} & $4 d$ & $\begin{array}{l}\text { 9-mm Aortic homograft-interrupted aortic } \\
\text { arch }\end{array}$ & $5.7 \mathrm{mo}$ & $\begin{array}{l}\text { Truncal valve repair, repair RPA stenosis, } \\
\text { repair supravalvar stenosis }\end{array}$ \\
\hline & & & $9.6 \mathrm{mo}$ & $\begin{array}{l}\text { Repair of RPA stenosis, resection of } \\
\text { homograft, direct connection (PTFE hood) }\end{array}$ \\
\hline 6 & $21 \mathrm{~d}$ & Direct connection (autologous pericardium) & $6.2 \mathrm{mo}$ & $\begin{array}{l}\text { Revision of outflow patch (aneurysmal) with } \\
\text { PTFE, repair of LPA }\end{array}$ \\
\hline 7 & $48 \mathrm{~d}$ & 10-mm Aortic homograft & $7.5 \mathrm{mo}$ & $\begin{array}{l}\text { Conduit replacement (15-mm aortic homograft), } \\
\text { repair LPV stenosis, repair RPA stenosis }\end{array}$ \\
\hline \multirow[t]{2}{*}{8} & $12 \mathrm{~d}$ & Direct connection (bovine pericardium) & $2.4 \mathrm{y}$ & Repair of RPA stenosis (PTFE) \\
\hline & & & 6.9 y & Repair of RVOT (PTFE) for stenosis \\
\hline 9 & $14 \mathrm{~d}$ & $\begin{array}{l}\text { 9-mm Aortic homograft-interrupted aortic } \\
\text { arch, PFO }\end{array}$ & $2.6 \mathrm{y}$ & Conduit replacement (15-mm aortic homograft) \\
\hline 10 & $23 d$ & Direct connection (bovine pericardium) & 3.7 y & $\begin{array}{l}\text { Repair origin of LPA and RPA (autologous } \\
\text { pericardium) }\end{array}$ \\
\hline 11 & $7 d$ & 10-mm Aortic homograft & 6.8 y & $\begin{array}{l}\text { Conduit replacement (21-mm aortic homograft), } \\
\text { repair branch PA stenosis }\end{array}$ \\
\hline 12 & $6 \mathrm{~d}$ & $\begin{array}{l}\text { 9-mm Pulmonary homograft-double aortic } \\
\text { arch }\end{array}$ & 8.9 y & $\begin{array}{l}\text { Conduit replacement (16-mm pulmonary } \\
\text { homograft) }\end{array}$ \\
\hline
\end{tabular}

$R V O T$, Right ventricular outflow tract; $P A$, pulmonary artery; $R P A$, right pulmonary artery; $L P A$, left pulmonary artery; $L P V$, left pulmonary vein.

Indications for operation include failure of adequate result in the above parameters with $\mathrm{CBI}$ or mild-to-moderate right-sided obstruction in a patient undergoing other cardiac procedures (eg, truncal valve replacement). Our indications for truncal valve replacement involve progressive and severe truncal insufficiency or stenosis with resultant left ventricular hemodynamic compromise.

\section{Echocardiography}

Perioperative and late postoperative transthoracic echocardiography was obtained to establish parameters of anatomy and ventricular function. Specifically, the degree of truncal valve insufficiency or stenosis, descending aortic Doppler flow, RVOT obstruction, pulmonary insufficiency, parameters of ventricular function and dilation, evidence of residual ventricular septal defects, and evidence of branch PA stenosis was evaluated. RVOT and PA obstruction, when present, were graded according to the following scale measuring peak gradients: mild, less than $40 \mathrm{~mm}$ $\mathrm{Hg}$; moderate, 40-60 mm Hg; and severe, greater than $60 \mathrm{~mm} \mathrm{Hg}$.

\section{Statistical Analysis}

Statistical methods were used to identify and estimate risk factors predicting the incidence of interventions (catheter-based, operative, or any intervention), as well as intervention-free survival. The methods of statistical analysis included the following: $\chi^{2}$ test for comparisons of dichotomous risk factors with negative outcomes, Mantel-Haenszel $\chi^{2}$ test for comparisons taking into consideration risk factor severity (eg, degree of valvular incompetence), and Wilcoxon test for comparisons of continuous variables with negative outcomes $(P<.05)$.

Logistic regression analysis of the cumulative incidence of interventions was used to evaluate the influence of these risk factors in a multivariable manner. Life-table estimates (KaplanMeier) were calculated by using the LIFETEST procedure of SAS 6.12 for PowerPC (SAS Institute, Cary, NC), with the log-rank test for difference between strata. The Cox regression model (using the PHREG procedure) was used to identify the most predictive variables. After univariate analysis, variables were entered into the models by using 3 selection criteria: forward, forward stepwise, and backward. The following variables were evaluated as follows: homograft, PTFE hood, bovine pericardium, autologous pericardium, cryopreserved pericardium, degree of valvular incompetence, year of operation, and age. Models were compared by using the $-2 \log \mathrm{L}$ score and the Wald score for significance. Threshold for entry into the model for both logistic regression and Cox regression was a $P$ value of less than .05 . This study received approval by the institutional review board.

\section{Results \\ Patients}

Between June 1990 and February 2004, 54 patients underwent primary repair of TA at the Children's Hospital of 
TABLE 2. Catheter-based interventions in the truncus arteriosus cohort

\begin{tabular}{|c|c|c|c|c|c|}
\hline Patient & Age & Operation & Interval & Intervention & Reintervention \\
\hline 1 & $30 \mathrm{~d}$ & 9-mm Aortic homograft & $3.8 \mathrm{mo}$ & RVOT balloon & Conduit stent 1.2 y later \\
\hline 2 & $13 d$ & $\begin{array}{l}\text { Direct connection-autologous } \\
\text { pericardium } \rightarrow \text { reoperation } 9 \mathrm{~d} \\
\text { later for RVOT obstruction }\end{array}$ & $3.8 \mathrm{mo}$ & LPA balloon-stent & $\begin{array}{l}\text { Bilateral branch PA balloon } \\
\text { angioplasty } 4.6 \text { mo later }\end{array}$ \\
\hline 3 & $7 d$ & 12-mm Aortic homograft & $6.3 \mathrm{mo}$ & RPA and LPA balloon & $\begin{array}{l}\text { RPA-LPA balloon } 4.6 \text { mo } \\
\text { later } \rightarrow \text { RPA balloon } 9.5 \text { mo } \\
\text { later } \rightarrow \text { reoperation } 5.1 \text { y later } \\
\text { conduit replacement, RPA- } \\
\text { LPA patch angioplasty }\end{array}$ \\
\hline 4 & $11 \mathrm{~d}$ & $\begin{array}{l}\text { Direct connection-autologous } \\
\text { pericardium }\end{array}$ & $7.3 \mathrm{mo}$ & RPA balloon & \\
\hline 5 & $16 \mathrm{~d}$ & $\begin{array}{l}\text { Direct connection-cryopreserved } \\
\text { pericardium }\end{array}$ & $7.4 \mathrm{mo}$ & RPA stent & \\
\hline 6 & $4 d$ & $\begin{array}{l}\text { Direct connection-cryopreserved } \\
\text { pericardium }\end{array}$ & $7.5 \mathrm{mo}$ & LPA balloon-stent & $\begin{array}{l}\text { LPA stent } 8.8 \text { mo later } \rightarrow \text { LPA } \\
\text { balloon } 16.6 \text { mo later }\end{array}$ \\
\hline 7 & $48 \mathrm{~d}$ & 10-mm Aortic homograft & $9 \mathrm{mo}$ & LPA balloon & $\begin{array}{l}\text { Conduit replacement } 1 \mathrm{~d} \text { later, } \\
\text { LPV repair }\end{array}$ \\
\hline 8 & $22 \mathrm{~d}$ & Direct connection-PTFE & $1.6 \mathrm{y}$ & RVOT balloon & \\
\hline 9 & $14 \mathrm{~d}$ & 9-mm Aortic homograft & $1.7 \mathrm{y}$ & RPA stent & $\begin{array}{l}\text { Balloon } 8.6 \text { mo } \rightarrow \text { conduit } \\
\text { replacement } 49 \text { d later }\end{array}$ \\
\hline 10 & $23 d$ & $\begin{array}{l}\text { Direct connection-bovine } \\
\text { pericardium }\end{array}$ & $1.7 \mathrm{y}$ & RVOT balloon & $\begin{array}{l}\text { Reoperation } 2 \text { y later-bilateral } \\
\text { PA patch angioplasty }\end{array}$ \\
\hline 11 & $11 \mathrm{~d}$ & $\begin{array}{l}\text { Direct connection-autologous } \\
\text { pericardium } \rightarrow \text { reoperation } 5 \text { mo } \\
\text { later for aneurysmal dilatation } \\
\text { of patch }\end{array}$ & $2.1 \mathrm{y}$ & LPA stent & $\begin{array}{l}\text { Bilateral branch PA stent } 2.9 \text { y } \\
\text { later, bilateral balloon } \\
\text { angioplasty } 1 \text { y later }\end{array}$ \\
\hline 12 & $10 d$ & 11-mm Aortic homograft & $3.6 \mathrm{y}$ & RPA balloon & \\
\hline 13 & $19 d$ & $\begin{array}{l}\text { Direct connection-bovine } \\
\text { pericardium }\end{array}$ & 5.3 y & LPA stent & \\
\hline 14 & $29 d$ & $\begin{array}{l}\text { Direct connection-bovine } \\
\text { pericardium }\end{array}$ & $6.7 \mathrm{y}$ & RPA stent & \\
\hline 15 & $14 \mathrm{~d}$ & $\begin{array}{l}\text { Direct connection-bovine } \\
\text { pericardium }\end{array}$ & $6.8 \mathrm{y}$ & RPA and LPA stent & \\
\hline 16 & $14 \mathrm{~d}$ & Direct connection-PTFE & 7.4 y & RPA balloon & \\
\hline 17 & $38 \mathrm{~d}$ & $\begin{array}{l}\text { Direct connection-autologous } \\
\text { pericardium } \rightarrow \text { reoperations } 2.9 \\
\text { mo later for aneurysmal } \\
\text { dilatation of patch }\end{array}$ & 8.2 y & RPA and LPA stent & \\
\hline 18 & $8 d$ & Direct connection-PTFE & 8.5 y & RVOT balloon & \\
\hline
\end{tabular}

RVOT, Right ventricular outflow tract; $L P A$, left pulmonary artery; $P A$, pulmonary artery; $R P A$, right pulmonary artery; $L P V$, left pulmonary vein.

New York. Of the 54 study patients, 15 (28\%) underwent $\mathrm{VH}$ repair, and 39 (72\%) underwent DC repair with a variety of hood materials to establish RV-PA continuity. One additional patient, who initially underwent repair with a VH conduit, ultimately underwent reoperation 10 months later and was converted to DC repair; all data after her reoperation were assigned to the DC cohort beginning at that time point.

The median age of the VH cohort was 16 days (range, 4-159 days), and that of the DC cohort was 13 days (range, 4-132 days). Truncus types according to the Collett-Edwards classification were type I $(\mathrm{n}=17$ [31.5\%]), type II $(\mathrm{n}=10$
[18.5\%]), transitional between types I and II ( $\mathrm{n}=23$ [42.6\%]), and type III $(n=4[7.4 \%])$. Associated lesions included patent foramen ovale-secundum atrial septal defect in 9 patients, anomalous coronary arteries in 8 patients (most often a single coronary artery), double aortic arch in 2 patients, and interrupted aortic arch in 6 patients (3 VH recipients and 3 DC recipients). DiGeorge syndrome was definitively diagnosed in 6 patients (2 VH recipients and $4 \mathrm{DC}$ recipients).

Patients were followed for a median of 4.6 years (range, 0-12.2 years). Thirteen patients were lost to follow-up after a median of 1.6 years (range, 7 days to 7.1 years), and these included $3 \mathrm{VH}$ recipients and $10 \mathrm{DC}$ recipients. Total 
TABLE 3. Mortality in the truncus arteriosus cohort

\begin{tabular}{ccccc}
\hline Patient & Age at repair & \multicolumn{1}{c}{ Operation } & Interval & Cause \\
\hline 1 & $10 \mathrm{~d}$ & DC (cryopreserved pericardium) & POD 0 & Biventricular failure \\
2 & $18 \mathrm{~d}$ & DC (homograft patch) & POD 0 & $\begin{array}{c}\text { Pulmonary hypertension/left upper lobe } \\
\text { pneumonia } \\
\text { Pulmonary hypertension/right lower lobe } \\
\text { pneumonia/low output }\end{array}$ \\
3 & $20 \mathrm{~d}$ & Pulmonary homograft & POD 1 & Pulmonary hypertension/ \\
4 & $4 \mathrm{~d}$ & Pulmonary homograft POD 1 & $\begin{array}{c}\text { RV failure } \\
\text { mo }\end{array}$ & $\begin{array}{c}\text { Sepsis/heart failure/medication } \\
\text { noncompliance }\end{array}$ \\
\hline
\end{tabular}

$D C$, Direct connection; $P O D$, postoperative day; $R V$, right ventricular.

follow-up (mean, median, range) for DC recipients was 1781 , 1749, and 0 to 4128 days, respectively, and that for $\mathrm{VH}$ recipients was 1957,1656 , and 0 to 4449 days, respectively $(P$ $=.6985)$. Overall, $17(30.9 \%)$ patients required a CBI, 12 $(21.8 \%)$ required reoperation for right-sided obstruction, and $21(38.2 \%)$ required either $\mathrm{CBI}$ or reoperation during the follow-up period.

\section{Operative Procedure}

Several hood materials were used for the DC as follows: autologous pericardium, $6(15 \%)$; bovine pericardium, 8 (20\%); cryopreserved pericardium, 7 (18\%); PTFE, 14 (35\%); and other, 5 (12\%; 3 homograft nonvalved PAs and 2 unknown). No patient underwent repair of the truncal valve at the time of the operation. Additional procedures performed at the time of truncus repair included the following: repair of interrupted aortic arch, 6 (11\%); closure of patent foramen ovale or secundum atrial septal defect, 5 (9.2\%); and division of double aortic arch, 2 (4\%). Seven $\mathrm{VH}$ recipients and 7 DC recipients required reoperation; 3 patients (2 DC recipients and $1 \mathrm{VH}$ recipients) required reoperation solely for truncal valve insufficiency and not for right-sided obstruction. These patients were censored from survival analysis addressing freedom from right-sided interventions at the time of their reoperation for truncal valve replacement. The specifics of the procedures performed for right-sided obstruction are collected in Table 1 (reoperations) and Table 2 (CBI).

\section{Echocardiography}

Thirty-six patients had echocardiographic follow-up within 2 years of the study's end. Although many patients had been seen more recently and often for more than 5 years of total follow-up, their echocardiographic data was not included in the analysis unless it was obtained within 2 years of the study termination date.

Truncal valve. Nine (25\%) patients had minimal, 15 (42\%) had mild, and 9 (25\%) had moderate truncal insufficiency; all patients with mild or less truncal valve insuf- ficiency had normal descending aortic Doppler measurements. Two $(5.5 \%)$ patients had mild truncal valve stenosis (peak gradients of 21 and $36 \mathrm{~mm} \mathrm{Hg}$, respectively).

$\boldsymbol{V H}$ recipients. Of the $9 \mathrm{VH}$ recipients for whom data were available, 3 (33\%) had minimal-to-mild RVOT obstruction, and $6(67 \%)$ had moderate RVOT obstruction. Five $(56 \%)$ had minimal-to-mild, 1 (11\%) had moderate, and $3(33 \%)$ had severe pulmonary insufficiency. All had normal ventricular function, and none had residual ventricular septal defects. Four (44\%) patients were free of and 5 $(56 \%)$ had mild branch PA stenosis.

DC recipients. Of the $27 \mathrm{DC}$ recipients for whom data were available, $19(70 \%)$ had minimal-to-mild, 7 (26\%) had moderate, and $1(4 \%)$ had severe RVOT obstruction. All were free of pulmonary insufficiency. All had normal ventricular function, and 2 had small residual ventricular septal defects. Eighteen (67\%) patients were free of branch PA stenosis, and $7(26 \%)$ had mild and $2(7 \%)$ had moderate branch PA stenosis. Of those patients free of branch PA stenosis or obstruction, 5 had undergone a prior CBI (3 underwent balloon angioplasty and 2 underwent stent placement).

\section{Morbidity and Mortality}

Five $(9.1 \%)$ patients died postoperatively, and their data are collected in Table 3 . Of particular note, 3 of the 5 deaths occurred before 1995, and the other 2 occurred in 1996 and 1999. With the exception of patient 5, who died late after repair, many of the deaths involved pulmonary hypertension. In addition to the major morbidities of reoperation and CBI, 2 patients required delayed sternal closure, and 2 additional patients had complete heart block requiring permanent pacemaker placement 9 months and 9.2 years after truncus repair, respectively.

\section{Outcomes}

Results are represented below for each of the outcomes studied (reoperation, CBI, and any intervention) in the following fashion: incidence of intervention in $\mathrm{VH}$ versus DC 


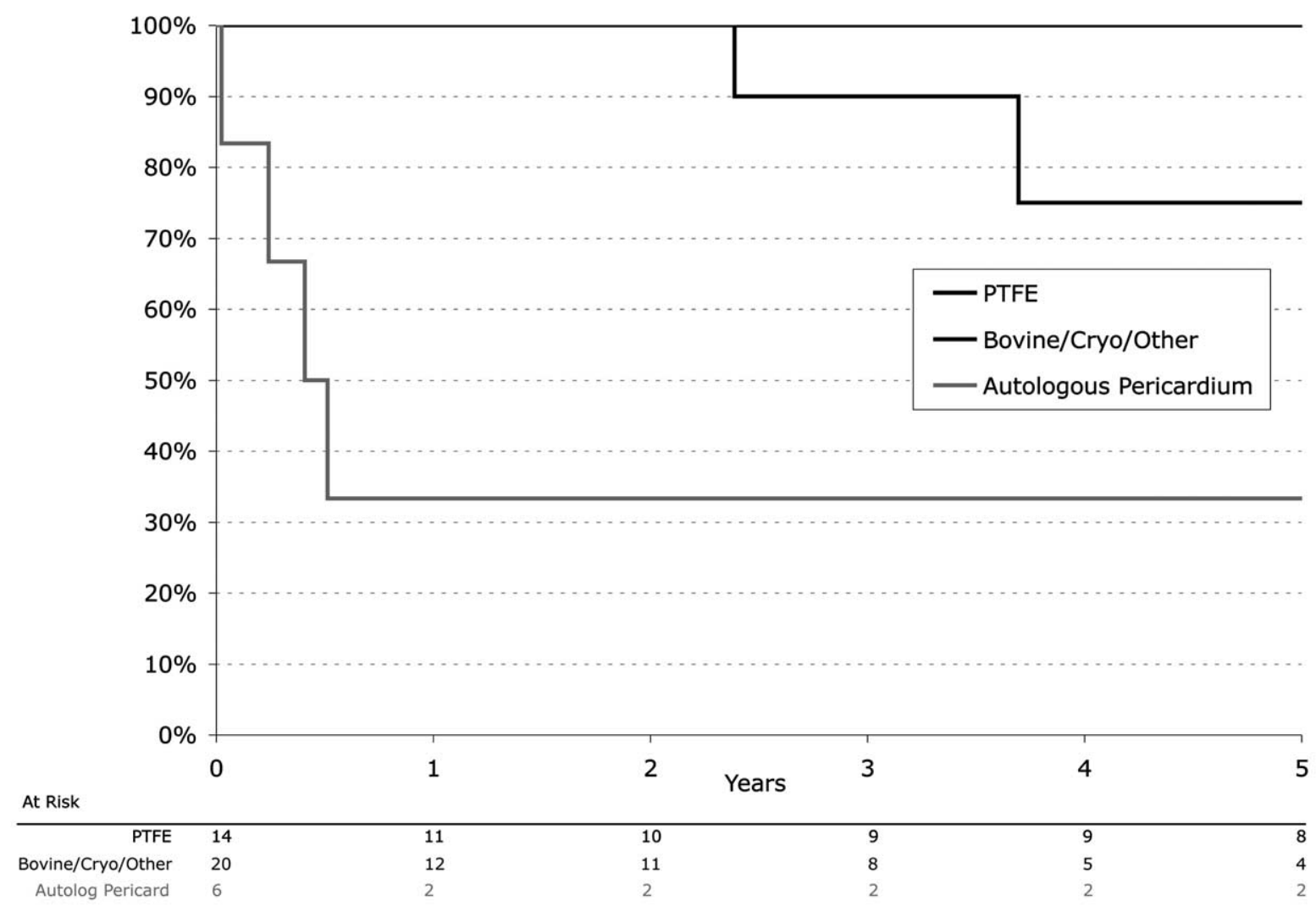

Figure 2. Kaplan-Meier survival function of freedom from reoperation for only those DC recipients, as stratified by hood type. Five-year survival estimates are illustrated for patients as a function of type of $D C(P=.0003)$.

recipients, univariate analysis on the basis of hood type, Kaplan-Meier estimates of intervention-free survival (stratified by operation type and hood type), and results of regression modeling of both overall incidence (logistic regression) and intervention-free survival (Cox proportional hazards). Results comparing hood types are reported comparing each type of hood with all other patients, including those receiving VHs; additional analysis was performed comparing hoods only among those receiving DCs, and the results were similar and not reported below.

Reoperation. VH recipients were more likely to require reoperation than DC recipients ( $40 \%$ vs $15 \%, P=.046)$. Among the DC recipients there was significant variation between reoperation rates. At the extremes, no patients $(0 \%$ vs $29.4 \%$ for all others, $P=.046$ ) with a PTFE hood required reoperation compared with $4(66.7 \%$ vs $16.3 \%$ for all others, $P=.005$ ) of those with autologous pericardial hoods. The incidence of reoperation in the groups was as follows: bovine pericardium, $2(P=.814)$; cryopreserved pericardium, $0(P=.170)$; PTFE, $0(P=.022)$; and other, $0(P=.170)$.

Kaplan-Meier estimates of survival free from reoperation were similar in both the DC and $\mathrm{VH}$ groups, although there was a trend toward improved reoperation-free survival among those with DCs $(P=.0713)$. However, among patients receiving DCs, there was a significant difference according to hood type $(P=.0003$, Figure 2$)$; in this analysis bovine pericardium, cryopreserved pericardium, and "other" (most often PA homograft tissue) were combined as a group. Factors predictive of need for earlier reoperation on the basis of a Cox model are compiled in Table 4. A logistic regression model predicting need for reoperation identified identical risk factors.

CBI. The incidence of CBI was similar among VH recipients (26.7\% [4/15]) and DC recipients (32.5\% [13/40]; $P=$.677). Patients undergoing reconstruction with autologous pericardial hoods were more likely to require CBI (66.7\% [4/6] vs $26.5 \%$ for all others, $P=.045)$. No other significant differences were noted: bovine pericardium, 4 of $8(50 \%, P=.206)$; cryopreserved pericardium, 2 of 6 $(P=.892)$; PTFE, 3 of $14(P=.374)$; and other, 0 of 6 $(P=.083)$. No specific preoperative anatomic diagnosis, demographic parameter, year, or operation or adjunctive operative procedure predicted the need for later CBI.

Neither univariate nor multivariable analyses demonstrated a predictor of the need for later CBI, and Kaplan- 
TABLE 4. Cox parametric regression of survival free from reoperation for right-sided obstruction (dependent variables) in the truncus cohort

\begin{tabular}{|c|c|c|c|c|c|c|}
\hline Variable & $\begin{array}{c}\text { Parameter } \\
\text { estimate }\end{array}$ & SE & Wald $\chi^{2}$ & $P$ value & $\mathbf{R R}$ & $95 \% \mathrm{Cl}$ \\
\hline Use of valved homograft & 1.975111 & 0.81705 & 5.84370 & .0156 & 7.207 & $1.453-35.478$ \\
\hline Use of autologous pericardium & 2.714667 & 0.86969 & 9.74324 & .0018 & 15.100 & $2.746-83.032$ \\
\hline
\end{tabular}

Criteria for assessing model fit (backward elimination provided best model): -2 Log L-without covariates, 81.586; with covariates, $68.748 \chi^{2}$ for covariates, 12.838; with $2 \mathrm{DF}(P=.0016)$; Wald $\chi^{2}$ for covariates, 9.837 with $2 \mathrm{DF}(P=.0073)$. RR, Risk ratio; $C l$, confidence interval.

TABLE 5. Cox parametric regression of survival free from any intervention for right-sided obstruction (dependent variables) in the truncus cohort

\begin{tabular}{|c|c|c|c|c|c|c|}
\hline Variable & $\begin{array}{l}\text { Parameter } \\
\text { estimate }\end{array}$ & SE & Wald $\chi^{2}$ & $P$ value & RR & $95 \% \mathrm{Cl}$ \\
\hline $\begin{array}{l}\text { Use of autologous } \\
\text { pericardium }\end{array}$ & 3.338378 & 0.78311 & 18.17303 & .0001 & 28.173 & $6.071-130.744$ \\
\hline Use of valved homograft & 1.871226 & 0.67906 & 7.59348 & .0059 & 6.496 & $1.717-24.585$ \\
\hline $\begin{array}{l}\text { Use of bovine } \\
\text { pericardium }\end{array}$ & 1.385416 & 0.66036 & 4.40151 & .0359 & 3.996 & $1.095-14.581$ \\
\hline Year of experience & 0.196801 & 0.08229 & 5.71910 & .0168 & 1.218 & $1.036-1.431$ \\
\hline Age of patient in days & -0.034181 & 0.01609 & 4.51059 & .0377 & 0.966 & $0.936-0.997$ \\
\hline
\end{tabular}

Criteria for assessing model fit (backward elimination provided best model): -2 Log L-without covariates, 34.871; with covariates, $111.827 ; \chi^{2}$ for covariates, 23.045 with $5 \mathrm{DF}(P=.0003)$; Wald $\chi^{2}$ for covariates, 20.515 with $5 \mathrm{DF}(P=.0010)$. $R R$, Risk ratio; $C l$, confidence interval.

Meier estimates of freedom from CBI demonstrated no difference between the VH and DC cohorts or among the different hood types of DC recipients. Neither logistic regression nor Cox multivariable modeling demonstrated significant predictors of earlier CBI.

Any intervention (reoperation or CBI). $\mathrm{VH}$ and $\mathrm{DC}$ recipients had similar incidences of the combined end point of reoperation or CBI (40.0\% [6/15] vs 37.5\% [15/40], $P=.865$ ). Those patients receiving autologous pericardial hoods were more likely to need intervention than all others $(83.3 \%[5 / 6]$ vs $32.6 \%, P=.041)$, whereas those in the other category were significantly less likely to need intervention compared with all others $(0.0 \%$ [0/6] vs $42.9 \%)$. The incidence of intervention for other types of DCs showed a trend toward decreased rates with PTFE hoods: bovine pericardium, 5 of $8(62.5 \%, P=.126)$; cryopreserved pericardium, 2 of $6(33.3 \%, P=.796)$; and PTFE, 3 of $14(21.4 \%, P=.135)$. No specific preoperative demographic parameter, year, or operation or adjunctive operative procedure predicted the need for any later intervention in univariate analysis.

Multivariable logistic regression analysis demonstrated only use of an autologous pericardial hood to be predictive of later intervention $(P=.04$; risk ratio, 10.3 ; $95 \%$ confidence interval, 1.111-95.760). Cox proportional hazard modeling demonstrated several other predictors of earlier intervention (Table 5). Although Kaplan-Meier estimates of freedom from any intervention did not demonstrate signif- icant differences between $\mathrm{VH}$ and $\mathrm{DC}$ recipients, statistical significance was evident when comparing DC recipients stratified by hood type $(P=.0034$, Figure 3$)$.

Functional outcomes. No child in the cohort at last follow-up has demonstrated exercise intolerance. Two children are currently being followed for truncal valve insufficiency, which, although progressive, has not yet warranted valve replacement.

\section{Discussion}

With increased experience and a wider availability of smaller-sized homografts, many have favored primary repair of the TA in infants and neonates. ${ }^{4-10}$ Considerable contention persists, however, as to the optimal method to establish RV-PA continuity. Reid and colleagues, ${ }^{2}$ in 1986, proposed the DC technique later popularized by BarberoMarcial and associates ${ }^{3}$ in 1990. Heralded as a method that uses autologous tissue (and in theory affords patient growth), the DC technique has been promoted for its likely delay (and potential avoidance) of later reoperation. However, not all reports have been uniformly favorable, and its use has been questioned because of the valveless connection created. ${ }^{11}$ At our institution, availability of homografts of appropriate sizes for neonatal repairs has not influenced our operative technique. Instead, we have favored DC, where anatomically appropriate, in the hopes of avoiding later conduit exchange; we also observed the need for later CBI on either the main RV-PA connection or branch PAs. 


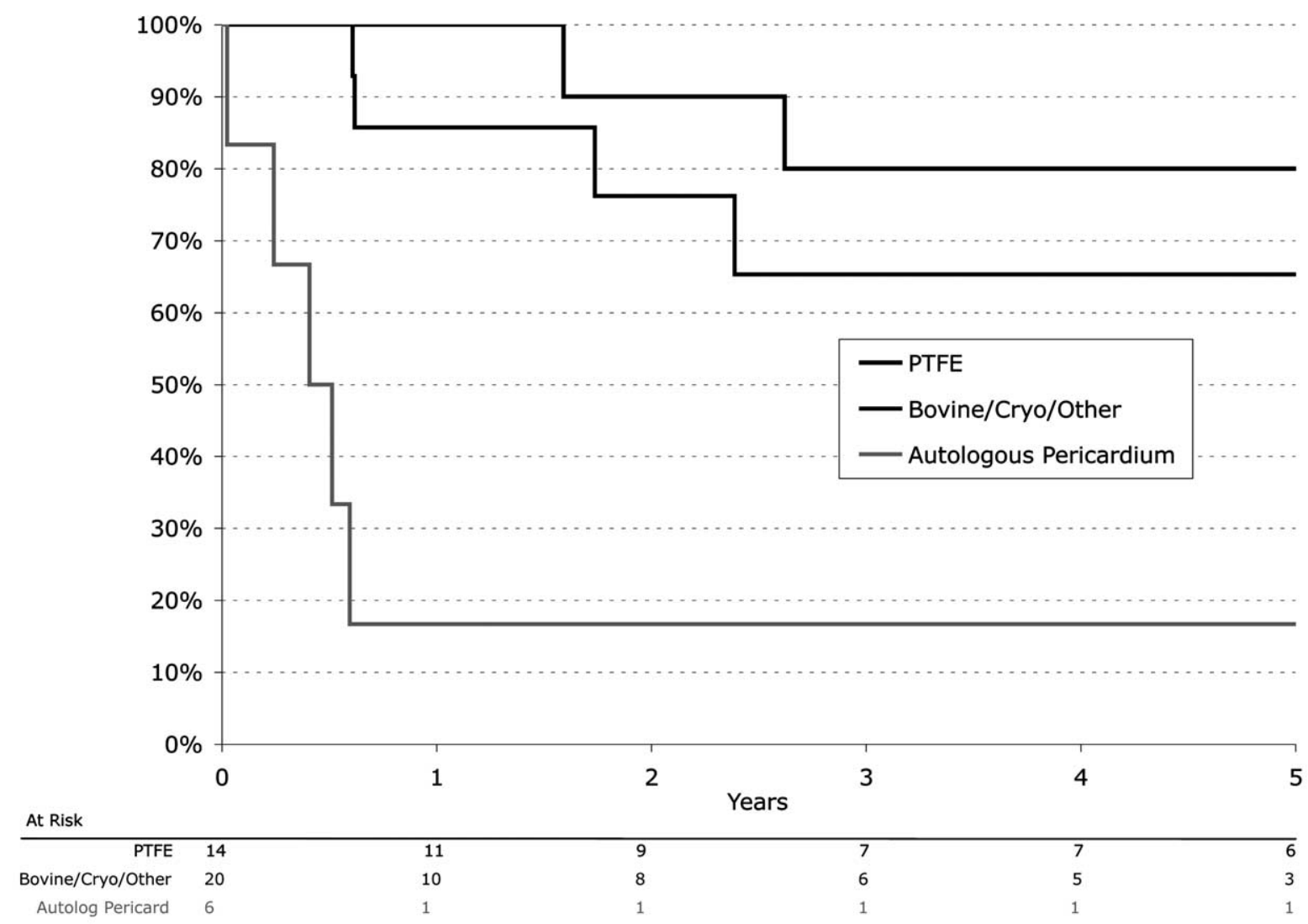

Figure 3. Kaplan-Meier survival function of freedom from any intervention for only those DC patients, as stratified by hood type. Five-year survival estimates are illustrated for patients as a function of type of $D C(P=.0034)$.

Our data here are notable for several key observations. First, VH recipients more frequently required reoperation for right-sided obstruction than DC recipients. Although all of the $\mathrm{VH}$ recipients receiving repairs in infancy will come to reoperation, we found it compelling that the DC recipients did not require as many. Early in our experience, we tended to use autologous pericardium (both treated and primarily untreated with gluteralehyde) as a DC hood. As demonstrated, several of these patients returned early $(<6$ months) for revision of their outflow patch, most often because of aneurysmal dilatation of the hood. We have since abandoned use of untreated autologous pericardium (we continue to use gluteraldehyde-treated autologous pericardium). Therefore eliminating these patients from the DC cohort likely would make the disparity between VH and DC recipients more pronounced. Indeed, with the exclusion of patients with autologous pericardial hoods, only 2 patients in the DC cohort required reoperation for persistent rightsided obstruction.

Second, $\mathrm{VH}$ and $\mathrm{DC}$ recipients required comparable CBIs for RVOT or PA stenosis. Those patients requiring CBI early ( $<2$ years) after primary operation often required additional CBI or reoperation thereafter. Of those DC re- cipients requiring $\mathrm{CBI}$, although 3 (23\%) required a second or third CBI, only 1 ultimately required reoperation. Moreover, the patients with a PTFE hood required CBI late $(2,7$, and 8.5 years) after initial repair. Thus although the DC technique might not prevent CBI, with appropriate intervention, it can help to reduce later reoperation.

Third, analysis of survival free from either reoperation or any intervention (CBI or reoperation) demonstrated similar findings, namely a trend toward improved freedom from either outcome in the DC group and, within the DC subcohort, a statistically significant difference in both outcomes according to hood material used. However, we were surprised to discover the substantial improvement in results because of the use of PTFE as hood material. Recent follow-up echocardiographic findings of both cohorts has been encouraging. We have followed a policy of aggressive intervention for branch PA stenosis, and analysis of most recent echocardiograms demonstrated a low incidence of significant PA stenosis in both study groups. Free pulmonary insufficiency (also present in one third of the $\mathrm{VH}$ recipients) has been well tolerated by the DC recipients.

Fourth, Cox multivariable analysis of survival free from any intervention demonstrated $\mathrm{VH}$ and autologous pericar- 
dial hood use and year of experience to most strongly predict any subsequent intervention. The findings related to year most likely reflect both a recent more aggressive strategy of CBIs in our institution, as well as the increasing availability of magnetic resonance imaging modalities disclosing significant RVOT obstruction earlier.

Finally, our perioperative management of these neonates appears to have improved significantly. Most of our mortality occurred before 1996, and the majority was caused by pulmonary hypertension. In recent years, we have favored the use of nitric oxide in the perioperative period and follow a policy of paralysis and sedation for all newborns immediately after repair. As others have emphasized, particularly in the setting of the valveless DC repair, avoidance of major pulmonary arterial vasoconstriction is essential. Thus assiduous mechanical ventilatory management, adequate pulmonary toilet, and the avoidance of atelectasis and consolidation are of utmost importance., ${ }^{2,12-14}$

We report excellent outcomes with surgical repair of TA in neonates and infants. When anatomically appropriate, a DC repair with PTFE demonstrated excellent durability with a low rate of later interventions. In recent years, CBIs have substantially reduced the need for reoperation and remain an essential feature of long-term management. Assiduous follow-up to guard against progressive ventricular failure, truncal valve dysfunction, significant disparity in pulmonary blood flow, or RVOT obstruction is critical, and early intervention in these settings is warranted.

Several limitations deserve comment. First, this evaluation is subject to the restrictions of a retrospective study; follow-up was difficult to obtain in patients who had moved far from the medical center or who had undergone repair in the distant past. Second, the regularity with which follow-up echocardiograms were obtained was quite variable. To adjust for this, we discarded echocardiographic data acquired more than 2 years before the study's end, regardless of the length of follow-up. Third, the degree to which right-sided obstruction was interrogated, and thus the potential for its intervention, remains reliant on the referring physician. Serial echocardiograms performed at regular intervals could elucidate further the progression of right-sided obstruction and thereby assist in regulating the process of its intervention.

We thank Mark Russo, MD, MS, for his kind statistical review of this manuscript.

\section{References}

1. McGoon D, Rastelli G, Ongley P. An operation for the correction of truncus arteriosus. JAMA. 1968;205:69-73.

2. Reid KG, Godman MJ, Burns JE. Truncus arteriosus: successful surgical correction without the use of a valve conduit. Br Heart J. 1986;56:388-90.

3. Barbero-Marcial ML, Riso A, Atik E, Jatene A. A technique for correction of truncus arteriosus types I and II without extracardiac conduits. J Thorac Cardiovasc Surg. 1990;99:364-9.
4. Hanley FL, Heinemann MK, Jonas RA, Mayer JE, Cook NR, Wessel DL, et al. Repair of truncus arteriosus in the neonate. $J$ Thorac Cardiovasc Surg. 1993;105:1047-56.

5. Pearl JM, Laks H, Drinkwater DC, Milgalter E, Charas OA, Giacobetti F, et al. Repair of truncus arteriosus in infancy. Ann Thorac Surg. 1991;52: 780-6.

6. Thompson L, McElhinney DB, Reddy M, Petrossian E, Silverman NH, Hanley FL. Neonatal repair of truncus arteriosus: continuing improvement in outcomes. Ann Thorac Surg. 2001;72:391-5.

7. Bove EL, Beekman RH, Snider R, Callow LB, Underhill DJ, Rocchini AP, et al. Repair of truncus arteriosus in the neonate and young infant. Ann Thorac Surg. 1989;47:499-506.

8. Bove EL, Lupinetti FM, Pridjian AK, Beekman RH, Callow LB, Snider AR, et al. Results of a policy of primary of truncus arteriosus in the neonate. J Thorac Cardiovasc Surg. 1993;105:1057-66.

9. Urban AE, Sinzobahamvya N, Brecher AM, Weter J, Malorny S. Truncus arteriosus: ten-year experience with homograft repair in neonates and infants. Ann Thorac Surg. 1998;66(suppl):S183-8.

10. Thompson LD, McElhinney DB, Reddy VM, Petrossian E, Silverman $\mathrm{NH}$, Hanley FL. Neonatal repair of truncus arteriosus: continuing improvement in outcomes. Ann Thorac Surg. 2001;72:391-5.

11. Lacour-Gayet F, Serraf A, Komiya T, Sousa-Uva M, Bruniaux J, Touchot A, et al. Truncus arteriosus repair: influence of techniques of right ventricular outflow tract reconstruction. $J$ Thorac Cardiovasc Surg. 1996;111:849-56.

12. Danton MHD, Barron DJ, Stumper O, Wright JG, DeGiovannni J, Silove ED, et al. Repair of truncus arteriosus: a considered approach to right ventricular outflow tract reconstruction. Eur J Cardiothorac Surg. 2001;20:95-104.

13. Peetz DJ, Spicer RL, Crowley DC, Sloan H, Behrendt DM. Correction of truncus arteriosus in the neonate using a nonvalved conduit. $J$ Thorac Cardiovasc Surg. 1982;83:743-6.

14. Spicer RL, Dehrendt D, Crowly DC, Dick M, Rocchini AP, Uzark K, et al. Repair of truncus arteriosus in neonates with the use of a valveless conduit. Circulation. 1984;70(suppl I):I26-9.

\section{Discussion}

Dr Constantine Mavroudis (Chicago, Ill). Dr Chen and his associates have presented their experience with repair of TA in 54 patients, with special consideration to the type of RV-PA continuity. I would like to congratulate the authors on their excellent clinical results and, in particular, Dr Chen on a very succinct presentation. This is a very difficult set of data to present, and I think you did so masterfully.

I have one comment and a few questions.

I note that you have used the Collett-Edwards classification. The trend has been to use the Van Praagh classification, which includes stratification for discontinuous PAs and interrupted aortic arches. Because you yourself, in this series, have reported 6 patients with interrupted aortic arches, it would seem logical that you might want to restratify your patient population.

Did your surgical group encounter any cases of discontinuous PAs, and how were these patients operatively managed?

Also, in those patients with interrupted aortic arches, was the time interval between primary repair and subsequent conduit revision shorter than in the other patients? And did the aortic arch repair adversely affect the conduit revision at the time of the reoperation?

The PTFE hood is somewhat stiff. We use this hood technique as well, except we use it with a valved conduit to complete the RV-PA continuity. We believe that this hood maintains its shape and therefore decreases the chances for stenosis by means of external compression from either the sternum or the other structures. I have heard this described as the PTFE hood "fights for its 
own territory." Is this your thought, or do you have any other possible interpretations for this. I think this is a very stark finding in your report because you have extended the operative interval in these patients for quite a long time.

Finally, do you have any experience with the Contegra valve conduit, that is to say, the bovine jugular vein conduit? We have seen accelerated and early distal stenosis with this graft, and I believe that Dr Van Garsse will be talking about his experience from Belgium tomorrow.

Dr Chen. With regard to your first question regarding discontinuous PAs, we had 4 patients who demonstrated that anatomic diagnosis, and they all fell into the homograft group. One is certainly less likely to be able to unifocalize discontinuous PAs and bring them up to the shoulder of the RV without some level of PA distortion.

With regard to the question about interrupted aortic arch, that anatomic diagnosis did not acquire significance as a separate risk factor for subsequent reoperation. And of the entire group, only one required any kind of patch aortoplasty of the aortic arch. The arch itself did not adversely affect the later conduit revision, nor did it need to be repaired itself.

We found the PTFE hood results to be surprising as well. It has been postulated, of course, that, at the other end of the spectrum, the pliability of autologous pericardium probably accounts for its dilatation. Accordingly, one could make the argument that conversely the less distensible PTFE might actually allow the transduction of ventricular pressures toward the PA and thereby encourage growth and, hopefully, promote less branch PA stenosis, but that is purely conjecture.

We do not have an independent experience with the Contegra graft, but I think certainly over the next few years we should be able to elicit some interesting information from the other centers where it is being used.

Dr Gerhard Ziemer (Tuebingen, Germany). We were using the repair without conduit for more than 15 years in a much smaller program, and I wonder whether you see a difference between pericardium and PTFE in your outcomes.

My question is this: Do you specifically look at the way you close your ventricular septal defect, namely, not bringing the ventricular septal defect patch, because it is sometimes necessary in the less than 3-kg patient, to the epicardium? Because once you would do that, then you would have a circumference just consisting of nongrowing tissue. Therefore do you specifically try to put the ventricular septal defect patch suture strictly endocardiallyintracardially?

Dr Chen. Certainly Dr Quaegebeur might wish to speak to this as well, but we certainly tried to do that as much as possible. But I think the other important thing to remember is that the level of obstruction in the DC recipients generally was not in the proximal PA. Although there might be that small area of nonviable tissue adjacent to the ventricular septal defect patch and the patch to the truncus, that is not the area that seems most often to be obstructed or kinked; it seems to be that the obstructions are more distally in the branch PAs. Therefore certainly, even though that area might not grow, it does not appear to be a nidus of obstruction.

Dr Ziemer. The DC is really prone to distortion at the bifurcation, and therefore this is one of the areas to take care of.

Dr Glen S. Van Arsdell (Toronto, Ontario, Canada). I congratulate you on a beautiful series and a beautiful presentation. The underlying premise of the surgical strategy is that having pulmonary insufficiency is better than having a conduit that will cause stenosis and require surgical or catheter reintervention. At least that is what I would derive from the strategy.

Those of us who have an adult congenital practice have had a great deal of concern about pulmonary insufficiency, as seen late in tetralogy of Fallot. I am wondering if you have had an opportunity to look at these patients in that regard (ie, to look at right ventricular end-diastolic dimension compared with left ventricular end-diastolic dimension). In adult congenital patients with pulmonary insufficiency, the bigger the ventricle is, the more likely you are going to have problems with wide QRS complexes and sudden death.

Dr Chen. We did not look specifically at the comparison between right ventricular and left ventricular end-diastolic dimensions. We did look, in the most recent echocardiogram, at the level or degree of right ventricular dilatation graded as mild, moderate, and severe. And none of these patients, even those with the free pulmonary insufficiency, fell into anything other than a mild-tomoderate status.

But it is a concern. It certainly was a concern of ours regarding the lack of a valve in this particular scenario. Nonetheless, to date, our patients appear to be tolerating the pulmonary insufficiency quite well.

Dr Tara Karamlou (Portland, Ore). I did not notice on your slides whether you had mentioned whether you were using cryopreserved aortic or pulmonary allografts for your reconstruction. Although truncus is a risk factor in many reports for earlier need for conduit replacement, I noticed your mean time was just about 9 years, which is a little bit longer than what has been reported in the literature.

Dr Chen. We used a combination of homografts, almost 50/50 between aortic and pulmonary, and there was no particular characteristic that accounted for one to be chosen over another. More often, it was availability, more than anything else, and appropriate sizing that accounted for homograft choice.

Dr Willem J. Daenen (Leuven, Belgium). To avoid PA distortion, we used the Lecompte maneuver, especially in truncus type 2 and 3. Did you use it?

Dr Chen. In none of these patients did we use the Lecompte maneuver. This strategy has been reported in the literature and certainly can help to reduce branch PA distortion. 